\title{
The Growth of Internet of Things (IoT) In The Management of Healthcare Issues and Healthcare Policy Development
}

\author{
Neyara Radwan \\ Abdulaziz University, Saudi Arabia \& Suez Canal University, Egypt, nrhassan@kau.edu.sa \\ Maged Farouk \\ Onaizah Colleges, Saudi Arabia \& Workers University, Egypt, magedfarouk5@gmail.com
}

\begin{abstract}
The internet of things is becoming a new sensation in the medical and healthcare field. Healthcare is one of the sustainable development areas across different regions. This study aims at developing an analysis of Internet of Things (IoT) in the healthcare sector for the purposes of achieving sustainable development. The study took a direction of applied descriptive research. The methodology applied was Fuzzy Analytical Hierarchy Process (FAHP). This is a single crosssection survey research. After data gathering, the agreed paired comparison matrices, allocated to weighted criteria and the priority of internet of things usage were determined. The two criteria, quality of life and economic prosperity had the highest priority for internet of things sustainable development in the healthcare system. Fall detection, dental health, and ultraviolet radiation were among the areas where IoT was found to be applied prominently.

Keywords: Internet of Things, Management, Healthcare, Development, FAHP
\end{abstract}

\section{Introduction}


The internet revolution in the past decades indicated that new technologies could affect all aspects of business. Today, ubiquitous communication has been made possible by new advancements in network connections, wireless technologies and sensors [1]. Communication across devices and communication between humans and devices has improved tremendously. Internet of things (IoT) has developed has become a new factor to consider in technology and how it is applied to achieve various goals and objectives for businesses [2]. IoT is a new ICT development that has a great potential to deliver on different business aspects. The medical and healthcare sector is also benefiting from different technologies and IoT is being applied in various aspects of healthcare service delivery. Therefore, the IoT has become one of the essential technology trends that has to be followed for organizations and industries to be effective in delivering their services [3].

The Internet of Things is a new development on the internet that empowers different objects to connect with each other. Prioritizing IoT is essential for the development of a sustainable healthcare sector. The connectivity between different devices is vital in creating solutions to be used in the management of different healthcare needs [4]. The development of smart technologies has been critical in enhancing the application of IoT in various healthcare platforms. The rise in the need for healthcare services has prompted the need to strategize and deliver highly effective and sustainable methods of delivering the needs of the society in terms of enhancing accessibility and affordability of healthcare services [5].

Healthcare resources are constrained and there is a need to develop an effective means through which the issue can be handled effectively. Developing a sustainable healthcare sector is vital in the delivery of healthcare services to all in the society [6]. For instance, in the developing world, healthcare services are not accessed by many people and there are limited resources to 
develop highly effective healthcare systems [7]. Internet of Things can be used in the healthcare system to enhance the delivery of services because there are many factors that come into play as the sector develops. It is important to have an effective means through which healthcare services can be delivered to people without any further straining of resources [8].

An important aspect of IoT is the way information is used. Data is critical in the development of IoT systems for effectiveness to be achieved in the application of the technology. Big data and big data analytics plays a vital role in the development of an effective means through which IoT can be applied in the healthcare sector [9] and [10]. The purpose of this study is to prioritize the functional areas in the healthcare sector where development of IoT can enhance sustainable development in the sector. [11] Economic prosperity and quality of life that people lead in the society is influenced by the nature of healthcare services available for people in the society [12].

\section{Industry Description}

The healthcare sector is essential in the society. The facilities are not adequate to serve all humanity effectively [13]. There are techniques that have been developed to ensure all people receive adequate healthcare services [14]. This is an essential factor to consider in the management of different issues that arise [44]. Technology has been embraced in the healthcare sector and there are tremendous advancements in terms of delivering effective services in the [15]. Some of the technologies have enhanced the analysis of the human body to identify different problems that they have and treatment can commence [16].

Improvements in data security and information security systems has been one of the important factors necessary in the delivery of effective means through which IoT develops [17]. This is an essential factor to consider in the development of various systems that are necessary in 
the management of different services in the healthcare system [18]. Blockchain technologies have been applied to ensure all transactions and data are safe in the application of IoT. Information security is one of the essential factors that should be used to deliver an effective IoT system and safeguard different sets of data from possible cyber-attacks [19].

\section{Literature Review}

The Internet of Things was used in 1999 for the first time. Different things had a digital identity where the identities could be used to ensure effectiveness is achieved in the communication between these devices and objects [20]. This was an important development in the society because it could be used for the delivery of an essential means through which different objects could be connected [45]. The internet played a vital role in developing IoT because it provided a platform on which the objects could communicate. People could communicate with objects and objects could communicate with each other easily to deliver different services [21]. The digital identities that are developed are used by the computer to manage the objects and that creates an effective means through which the devices can be used to deliver different forms of communication within the devices and between the devices and humans [46].

Today, the internet connects people but IoT connects objects. The available applications such as the ones used in smartphones are used to control the objects for effectiveness to be achieved in the delivery of different services [47]. IoT has led to the development of capabilities of sending data and different forms of information across a network [46].

Big data has become an essential asset in healthcare. Practitioners are able to diagnose people and develop effective interventions because they can access different data which creates effective information to be used in the delivery of healthcare services [22] [23]. Smart devices have been developed and they can give information about patients. Wearable devices are vital in 
managing different healthcare issues because they monitor individuals' health statuses [24]. Monitoring the body is essential in identifying problems early and sending signals that medical attention is required for such individuals. This has been an essential factor in delivering healthcare services to people who otherwise would be having problems. [25] Technology has been embraced in the healthcare sector making it highly effective in managing [26]. The Internet of Things is likely to enhance the delivery of these services to the community [48].

Integrating technology in the healthcare sector has become an important aspect that will deliver a highly effective means through which different issues in the healthcare sector can be solved [27]. IoT is an important development in the sector where there is a need to deliver an effective means through which services are delivered in the [28]. The healthcare industry has developed over time because of technology. It is important for policy makers in various medical facilities to encourage the application of IoT in the management of different healthcare issues [29] IoT is important because the devices used in the medical field can communicate with each other and perform various analyses which are essential in managing different healthcare situations [30]. Developing solutions is made easier with these technologies in the sector. It is important to have highly effective means through which healthcare services can be delivered through engaging the effective technologies [49].

In business, most organizations are focusing more on IoT and that has an impact on how they deliver on the services that they provide in the different sectors. Customer relationship management has been made easier in business because it is through such a factor that different issues can be managed effectively (Ghazal et al., 2021) [50]. The internet of Things has served different businesses well by ensuring there is effectiveness in the way they handle different services. In the medical field, the technology has played a vital role in delivering various services 
to individuals more effectively [51]. A lot of improvements have been experienced in the healthcare sector as a result of having highly effective means through which different issues are managed. Different IoT-based technologies have been developed for the healthcare sector and it is because of such developments that it has been essential in building a highly effective means through which the healthcare system can benefit from these developments in technology [31]. Applying IoT in medicine is vital in enhancing sustainable development in the healthcare sector.

\section{Smart Health}

The Internet of Things has a promising future for e-health. In fact, some technologies have been developed based on IoT and they are effective in managing different healthcare issues for patients. According to Aladwani (2019) [32] ongoing monitoring of people or patients is essential in the delivery of an effective means through which prevention of diseases can be achieved. Sharma and Tripathi (2020) [33] deduce that the devices used in monitoring people's health are essential in developing an effective means through which their quality of life improves. Verdejo et al. (2021) argue that the smart technology has been an essential factor in the healthcare sector since there are many different factors that can be used to communicate various issues regarding the patient needs [52]. Patients are empowered because they are able to develop a means through which they can access different medical services as a result of managing themselves. Chandy (2019) [34] argues that using IoT provides various platforms that can be used to deliver vital information for the management of various healthcare issues. When a patient has access to different forms of information, it becomes easy for them to manage themselves and achieve the most desired outcomes [35]. There are different services that are available for the IoT technology in medicine as discussed in subsequent sections. 
Fall Detection - Patient falls are a common phenomenon. The application of IoT on patients who are at risk makes it easy for them to be monitored and managed effectively to mitigate the risk of falls. Patient falls can be mitigated through having effective technologies that will monitor incapacitated patients [36]

Sportsmen Care - Athletes' health is supposed to be monitored and that can be done through wearable devices which monitor their bodies and detect any anomalies. These devices are vital in managing different issues for effectiveness to be achieved [53].

Chronic Disease Management - Reducing the number of patients in the healthcare facilities is vital. This is achieved through remote management of chronic diseases where patients can monitor themselves and doctors can access information regarding their progress [37].

\section{Indicators of IoT Sustainability in Healthcare}

Sustainable development of the healthcare sector is vital because there is an increase in the need for these services [41]. The Internet of Things is the one that will be used to deliver an effective means of offering healthcare services which will be used to manage different issues in the healthcare sector [38]. The quality of life people lead is critical for the improvement of the quality of life they lead. The application of technology in the healthcare sector is a vital source of having a highly sustainable healthcare sector because it will ease the pressure on the healthcare facilities and enhance the performance of different healthcare service providers [39]. Technology is sustainable in all fields and the healthcare sector has to embrace it for sustainable development. Technology should be given top priority in the medical field because it is evident that improvements in the sector have come as a result of embracing technology [54].

\section{Conceptual Model}


The conceptual model chosen for the study which prioritizes the use of IoT for sustainable development of the healthcare sector is Fuzzy Analytical Hierarchy Process (FAHP).

\section{Methodology}

This study applied descriptive non-experimental research. The Fuzzy Analytical Hierarchy Process (FAHP) was applied in weighting the prioritization of IoT in the healthcare sector [40]. In the beginning, each of the economic prosperity, quality of life and environmental protection criteria were weighted. Various criteria were applied to develop an understanding of the healthcare environment. Comparison questionnaires were developed and applied to analyze the nature of the environment. The application of IoT in each of the healthcare sector was compared applying the different criteria. A decision matrix was then obtained from the analysis of the results. The statistical population comprised of experts who are aware of the applications of IoT in the healthcare system. The snowball method was then applied because of the limited number of experts that were used in this research.

\section{Fuzzy Analytical Hierarchy Process (FAHP).}

1. Fuzzy Analytical Hierarchy Process (FAHP). Is a multifactor decision making process that was developed by professor Saaty. This was an essential model to apply for this study because it covers various aspects of the parameters effectively. The process of applying FAHP is described below.

2. Evaluating literature to determine sustainability criteria and the use of IoT applications within the healthcare sector.

3. Forming a decision team to ascertain validity of questionnaire.

4. Distributing questionnaire and developing paired comparisons matrix.

5. Weighing of the criteria. 
Table: 1. Ranking of the IoT usage in the healthcare sector using the FAHP method.

\begin{tabular}{|c|c|c|c|}
\hline $\begin{array}{l}\text { Intensity of } \\
\text { importance }\end{array}$ & Fuzzy number & Definition & Membership function \\
\hline 9 & 9 & Extreme importance & $(8,9,10)$ \\
\hline 7 & 7 & $\begin{array}{l}\text { Very strong } \\
\text { importance }\end{array}$ & $(6,7,8)$ \\
\hline 5 & 5 & strong importance & $(4,5,6)$ \\
\hline 3 & 3 & $\begin{array}{l}\text { Moderate in } \\
\text { importance }\end{array}$ & $(2,3,4)$ \\
\hline 1 & 1 & Equal importance & $(1,1,2)$ \\
\hline
\end{tabular}

\section{Analysis and Results}

Determination of the weighting criterion was conducted after having several meetings for the purposes of filling the questionnaires. The paired comparison criterion was applied and using FAHP, weights were obtained and a decision matrix developed. Each option's weight was applied to deliver an effective means through which the matrix was developed.

\section{Ranking of Options}

Using the weights obtained for sustainable development criteria and decision matrix, the final rank for the application of IoT in each of the healthcare sector was achieved.

Table: 2. Weight of criteria sustainability

\begin{tabular}{|l|l|l|}
\hline Economic Prosperity & Quality of Life & Environment protection \\
\hline $45.32 \%$ & $31.05 \%$ & $23.63 \%$ \\
\hline
\end{tabular}


Table: 3. Decision matrix as it was derived from average weights of each criterion.

\begin{tabular}{|l|l|l|l|}
\hline Options & Economic criteria of & Quality of life & Environment \\
\hline Fall detection & 0.109 & & protection \\
\hline Medical fridges & 0.084 & 0.096 & 0.14 \\
\hline Sportsmen healthcare & 0.069 & 0.11 & 0.039 \\
\hline Patient surveillance & 0.117 & 0.0136 & 0.153 \\
\hline Chronic diseases & 0.079 & 0.0954 & 0.121 \\
\hline management & & 0.104 & 0.025 \\
\hline Ultra violet radiation & 0.113 & & 0.176 \\
\hline Hygienic hand control & 0.098 & 0.132 & 0.12 \\
\hline Sleep control & 0.068 & 0.094 & 0.167 \\
\hline Dental health & 0.183 & 0.143 & \\
\hline
\end{tabular}

Table: 4. Scores according to priority

\begin{tabular}{|l|l|l|}
\hline Options & Ranking & Score \\
\hline Ultra violet radiation & 1 & 0.0567 \\
\hline Dental health & 2 & 0.0555 \\
\hline Fall detection & 3 & 0.0374 \\
\hline Patient surveillance & 4 & 0.0371 \\
\hline Hygiene hand control & 5 & 0.0340 \\
\hline Sportsmen healthcare & 6 & 0.0311 \\
\hline Sleep control & 7 & 0.0297 \\
\hline
\end{tabular}




\begin{tabular}{|l|l|l|}
\hline Medical fridges & 8 & 0.0271 \\
\hline Chronic diseases management & 9 & 0.0247 \\
\hline
\end{tabular}

\section{Conclusions}

According to the results of this study, it is evident that economic prosperity is one of the criteria that has the highest ranking with $45.32 \%$. Investing more in IoT in this sector will lead to automatic improvement in the other sectors. Satisfaction of hospital personnel is key to the improvement of healthcare service provision. This is an important observation that should be followed in the delivery of effective healthcare services as IoT is implemented in the sector [42].

The application of IoT in the hospitals was done and from the analysis, it is evident that the use of technology is more observed in the hospital where ultraviolet radiation is used. This is one of the ways through which various examinations are carried out to detect diseases or anomalies in the body [43]. The order in which various applications of IoT are implemented in hospitals has been developed in table 4 and it shows the nature of investment that should be done in the healthcare sector to improve its performance.

\section{Recommendations}

The need for embracing IoT is evident and there is a need for policy makers to ensure there is effective management of resources to deliver an effective means through which the individuals can achieve various improvements in the healthcare sector. Embracing IoT in healthcare would be essential in achieving sustainable development of the sector. This is because there will be a reduction in the pressure that is exerted on the healthcare facilities. When patients can manage themselves remotely, it becomes easy for the healthcare facilities to attend to other critical cases more effectively. 


\section{References:}

[1] K. N. V. \&. S. G. Jayavel, "An Analysis of IOT Test beds with Application in the Field of Medicine and Health Care.," Research Journal of Pharmacy and Technology,, vol. 10, no. 12, p. 4155, 2017.

[2] A. K. D. \&. G. T. Mohammed, "Information Technology Ethics and Professional Responsibilities.," International Journal of Advanced Science and Technology., vol. 4, no. 29, pp. 11336-11343., 2020.

[3] D. K. a. T. G. A M Mohammed, "Information Technology Ethics and Professional Responsibilities," International Journal of Advanced Science and Technology., 2020.

[4] G. T. A. M. K. D. A. M. A. H. Svoboda P., " Information Systems Integration to Enhance Operational Customer Relationship Management in the Pharmaceutical Industry. I," Advances in Intelligent Systems and Computing,, vol. 1377, no. 1, p. 21.

[5] S. V. \&. T. G. R. Zanjal, "Medicine Reminder and Monitoring System for Secure Health Using IOT.," Procedia Computer Science,, vol. 78, no. 1, pp. 471-476, 2016.

[6] J. W. X. H. W. W. X. \&. W. S. Huang, "Internet of things in health management systems: A review. International," Journal of Communication Systems, vol. 34, no. 4, 2020.

[7] F. H. M. A. F. M. K. S. D. M. Y. \&. J. S. Ullah, "Semantic interoperability for big-data in heterogeneous IoT infrastructure for healthcare.," Sustainable Cities and Society, vol. 34, pp. 90-96, 2017.

[8] M. Y. P. S. M. K. Y. K. C. D. \&. (. Jae Lim, "Senior Living Space Architecture Design based on Iot Devices Using Vital Sensors.," International Journal of Engineering \& Technology, vol. 7, no. 3, p. 120, 2018.

[9] Y. C. G. D. H. Y. X. K. M. \&. C. M. Zhang, "Real-Time Remote Health Monitoring System Driven by 5G MEC-IoT.," Electronics, vol. 9, no. 11, p. 1753, 2020.

[10] F. M. e. al., "Software Defect Prediction Using Ensemble Learning," A Systematic Literature Review,"inIEEEAccess, vol. 9, pp. 98754-98771, 2021.

[11] M. A. M. K. H. M. H. M. S. F. e. a. T. M. Ghazal, "Hep-pred: hepatitis c staging prediction using fine gaussian svm," Computers, Materials \& Continua, vol. 69, no. 1, p. 191203, 2021.

[12] B. F. Chioma, "Internet of Things (IoT): A Review of Enabling Technologies, Challenges and Open Research Issues.," International Journal for Research in Applied Science and Engineering Technology,, vol. 8, no. 4, pp. 277-285, 2020.

[13] M. N. R. M. M. B. M. M. \&. S. Bhuiyan, "Internet of Things (IoT): A Review of Its Enabling Technologies in Healthcare Applications, Standards Protocols, Security, 
and Market Opportunities.," IEEE Internet of Things Journal, vol. 8, no. 13, p. 10474-10498, 2021.

[14] B. F. F. C. V. B. M. C. N. \&. M. K. Farahani, "Towards fog-driven IoT eHealth: Promises and challenges of IoT in medicine and healthcare.," Future Generation Computer Systems, vol. 78, p. 659-676, 2018.

[15] J. S. T. D. \&. M. J. L. (. Mboli, "An Internet of Things-enabled decision support system for circular economy business model.," Software: Practice and Experience. , 2020.

[16] H. N. Z. Z. \&. Z. Y. Dai, "Blockchain for Internet of Things: A Survey.," IEEE Internet of Things Journal, vol. 6, no. 5, p. 8076-8094., 2019.

[17] T. E. a. Ghazal, "Security vulnerabilities, attacks, threats and the proposed countermeasures for the Internet of Things applications.," Solid State Technology. , vol. 63, no. 1s, pp. 2513-252, 2020.

[18] I. H. Sarker, "A machine learning based robust prediction model for real-life mobile phone data.," Internet of Things, vol. 5, p. 180-193, 2019.

[19] L. \&. B. R. Chettri, "A Comprehensive Survey on Internet of Things (IoT) Toward 5G Wireless Systems," IEEE Internet of Things Journal, vol. 7, no. 1, pp. 16-32, 2020.

[20] N. \&. T. A. Miloslavskaya, "Internet of Things: information security challenges and solutions.," Cluster Computing, vol. 22, no. 1, p. 103-119., 2018.

[21] M. A. M. A. a. D. K. Taher M. Ghazal, "Data Mining and Exploration: A Comparison Study among Data," Talent Development and Excellence, vol. 12, no. 1, p. 38543861, 2020.

[22] J. H. K. A. \&. P. J. Nord, "The Internet of Things: Review and theoretical framework.," Expert Systems with Applications, vol. 13, p. 97-108., 2019.

[23] M. S. Ali, "Applications of Blockchains in the Internet of Things: A Comprehensive Survey.," IEEE Communications Surveys \& Tutorials, vol. 21, no. 2, p. 1676-1717, 2019.

[24] E. S. A. H. S. J. U. \&. G. M. Sisinni, "Industrial Internet of Things: Challenges, Opportunities, and Directions.," IEEE Transactions on Industrial Informatics, vol. 14, no. 11, p. 4724-4734, 2018.

[25] T. R. S. H. M. A. T. M. G. M. T. A. Rabab Naqvi, "The Nexus Between Big Data and Decision-Making: A Study of Big Data Techniques and Technologies," The International Conference on Artificial Intelligence and Computer Vision, pp. 838$853,2021$.

[26] R. P. J. M. H. A. \&. S. R. (. Singh, "Internet of things (IoT) applications to fight against COVID-19 pandemic. Diabetes \& Metabolic Syndrome:," Clinical Research \& 
Reviews,, vol. 14, no. 4, p. 521-524., 2018.

[27] K. B. M. A. R. A. E. S. \&. B. Aarika, "Perception layer security in the internet of things.," Procedia Computer Science,, vol. 175, p. 591-596, 2020.

[28] A. D. S. \&. O. Oracevic, "Security in internet of things: A survey," 2017 International Symposium on Networks," Computers and Communications (ISNCC), pp. 1-6, 2017.

[29] N. \&. T. A. Miloslavskaya, " IoT BlockSIEM for information security incident management in the internet of things ecosystem.," Cluster Computing, vol. 23, no. 3, p. 1911-1925, 2020.

[30] Q. \&. L. S. Ibrahim, "An Insight Review of Internet of Things (IoT) Protocols, Standards, Platforms, Applications and Security Issues. International," Journal of Sensors, Wireless Communications and Control, vol. 10, 2020.

[31] F. H. M. A. F. M. K. S. D. M. Y. \&. J. Ullah, "Semantic interoperability for big-data in heterogeneous IoT infrastructure for healthcare.," Sustainable Cities and Society, vol. 34, pp. 90-96, 2017.

[32] T. Aladwani, "Scheduling IoT Healthcare Tasks in Fog Computing Based on their Importance.," Procedia Computer Science, vol. 163, p. 560-569, 2019.

[33] N. L. R. J. L. M. M. F. \&. E. M. E. Verdejo Espinosa, "Application of IoT in Healthcare: Keys to Implementation of the Sustainable Development Goals.," Sensors, vol. 21, no. 7, p. 2330., 2021.

[34] A. Chandy, "A Review On IoT Based Medical Imaging Technology For Healthcare Applications.," Journal of Innovative Image Processing, vol. 1, no. 1, pp. 51-60, 2019.

[35] G. \&. K. S. Sharma, "A Lightweight User Authentication Scheme for Cloud-IoT Based Healthcare Services.," Iranian Journal of Science and Technology, Transactions of Electrical Engineering,, vol. 43, no. s1, p. 619-636, 2018.

[36] M. H. L. M. v. B. L. B. E. C. R. G. I. I. Coahran, "Automated Fall Detection Technology in Inpatient Geriatric Psychiatry: Nurses' Perceptions and Lessons Learned.," Canadian Journal on Aging / La Revue Canadienne Du Vieillissement, vol. 37, no. 3, p. 245260, 2018.

[37] S. S. F. B. Z. \&. I. A. Zeadally, "Smart healthcare," PSU Research Review, vol. 4, no. 2, p. 149-168., 2019.

[38] J. \&. G. L. Tian, "Using data monitoring algorithms to physiological indicators in motion based on Internet of Things in smart city.," Sustainable Cities and Society, vol. 67, 2021. 
[39] M. Y. J. H. L. H. M. S. \&. M. G. Chen, "Urban Healthcare Big Data System Based on Crowdsourced and Cloud-Based Air Quality Indicators," IEEE Communications Magazine, vol. 56, no. 11, p. 14-20, 2018.

[40] S. S. Y. \&. I. M. Shah, "Analysis of barriers to the adoption of cleaner energy technologies in Pakistan using Modified Delphi and Fuzzy Analytical Hierarchy Process.," Journal of Cleaner Production, vol. 235, p. 1037-1050, 2019.

[41] H. Alzoubi, M. Alshurideh, B. Al Kurdi, and M. Inairat, "Do perceived service value, quality, price fairness and service recovery shape customer satisfaction and delight? A practical study in the service telecommunication context," Uncertain Supply Chain Manag., vol. 8, no. 3, pp. 579-588, 2020, doi: 10.5267/j.uscm.2020.2.005.

[42] M. Alshurideh, A. Gasaymeh, G. Ahmed, H. Alzoubi, and B. Al Kurd, "Loyalty program effectiveness: Theoretical reviews and practical proofs," Uncertain Supply Chain Manag., vol. 8, no. 3, pp. 599-612, 2020, doi: 10.5267/j.uscm.2020.2.003.

[43] H. M. Alzoubi and R. Yanamandra, "Investigating the mediating role of information sharing strategy on agile supply chain," Uncertain Supply Chain Manag., vol. 8, no. 2, pp. 273-284, 2020, doi: 10.5267/j.uscm.2019.12.004.

[44] B. Al Kurdi, H. Elrehail, and H. M. Alzoubi, “THE INTERPLAY AMONG HRM PRACTICES , JOB SATISFACTION AND INTENTION TO LEAVE : AN EMPIRICAL INVESTIGATION,” no. August, 2021.

[45] H. M. Alzoubi, G. Ahmed, A. Al-Gasaymeh, and B. Al Kurdi, "Empirical study on sustainable supply chain strategies and its impact on competitive priorities: The mediating role of supply chain collaboration," Manag. Sci. Lett., vol. 10, no. 3, pp. 703-708, 2020, doi: 10.5267/j.msl.2019.9.008.

[46] H. M. Alzoubi and R. Aziz, "Does emotional intelligence contribute to quality of strategic decisions? The mediating role of open innovation," J. Open Innov. Technol. Mark. Complex., vol. 7, no. 2, 2021, doi: 10.3390/joitmc7020130.

[47] S. Joghee, H. M. Alzoubi, and A. R. Dubey, "Decisions effectiveness of FDI investment biases at real estate industry: Empirical evidence from Dubai smart city projects," Int. J. Sci. Technol. Res., vol. 9, no. 3, pp. 3499-3503, 2020.

[48] A. Q. M. Alhamad, I. Akour, M. Alshurideh, A. Q. Al-Hamad, B. Al Kurdi, and H. Alzoubi, "Predicting the intention to use google glass: A comparative approach using machine learning models and PLS-SEM," Int. J. Data Netw. Sci., vol. 5, no. 3, pp. 311320, 2021, doi: 10.5267/j.ijdns.2021.6.002.

[49] T. M. Ghazal et al., "IoT for Smart Cities: Machine Learning Approaches in Smart Healthcare-A Review," Futur. Internet, vol. 13, no. 8, p. 218, 2021, doi: 10.3390/fi13080218.

[50] S. Hamadneh, O. Pederson, M. Alshurideh, B. Al Kurdi, and H. Alzoubi, “AN INVESTIGATION OF THE ROLE OF SUPPLY CHAIN VISIBILITY INTO THE AN INVESTIGATION OF THE ROLE OF SUPPLY CHAIN VISIBILITY INTO THE SCOTTISH BLOOD,” no. September, 2021. 
[51] H. Alzoubi and G. Ahmed, "Do TQM practices improve organisational success? A case study of electronics industry in the UAE," Int. J. Econ. Bus. Res., vol. 17, no. 4, pp. 459472, 2019, doi: 10.1504/IJEBR.2019.099975.

[52] M. A. Alnuaimi, H. M. Alzoubi, and N. N. Alnazer, "Analysing the appropriate cognitive styles and its effect on strategic innovation in Jordanian universities," Int. J. Bus. Excell., vol. 13, no. 1, p. 127, 2017, doi: 10.1504/ijbex.2017.10006235.

[53] Ghazal, T. M., Noreen, S., Said, R. A., Khan, M. A., Siddiqui, S. Y. et al. (2022). Energy Demand Forecasting Using Fused Machine Learning Approaches. Intelligent Automation \& Soft Computing, 31(1), 539-553.

[54] Ghazal, T.M. Internet of Things with Artificial Intelligence for Health Care Security. Arab J Sci Eng (2021). https://doi.org/10.1007/s13369-021-06083-8

[57] Aslam, M. S., Ghazal, T. M., Fatima, A., Said, R. A., Abbas, S. et al. (2021). EnergyEfficiency Model for Residential Buildings Using Supervised Machine Learning Algorithm. Intelligent Automation \& Soft Computing, 30(3), 881-888.

[58] Ghazal, T. M., Hussain, M. Z., Said, R. A., Nadeem, A., Hasan, M. K. et al. (2021). Performances of K-Means Clustering Algorithm with Different Distance Metrics. Intelligent Automation \& Soft Computing, 30(2), 735-742.

[59] Khan, Q., Ghazal, T. M., Abbas, S., Khan, W. A., Khan, M. A. et al. (2021). Modeling Habit Patterns Using Conditional Reflexes in Agency. Intelligent Automation \& Soft Computing, 30(2), 539-552.

[60] Rehman, E., Khan, M. A., Soomro, T. R., Taleb, N., Afifi, M. A., \& Ghazal, T. M. (2021). Using Blockchain to Ensure Trust between Donor Agencies and NGOs in UnderDeveloped Countries. Computers, 10(8), 98. doi:10.3390/computers10080098

[61] Ghazal, T.M. Positioning of UAV Base Stations Using 5G and Beyond Networks for IoMT Applications. Arab J Sci Eng (2021). https://doi.org/10.1007/s13369-021-05985-X

[63] Ghazal, T.M., Said, R.A. \& Taleb, N. Internet of vehicles and autonomous systems with AI for medical things. Soft Comput (2021). https://doi.org/10.1007/s00500-021-06035-2

[64] Matloob, Faseeha \& Ghazal, Taher \& Taleb, Nasser \& Aftab, Shabib \& Ahmad, Munir \& Khan, Muhammad \& Abbas, Sagheer \& Soomro, Tariq. (2021). Software Defect Prediction Using Ensemble Learning: A Systematic Literature Review. IEEE Access. 9. 98754-98771. 10.1109/ACCESS.2021.3095559.

[65] T. M. Ghazal, M. Anam, M. K. Hasan, M. Hussain, M. S. Farooq et al., "Hep-pred: hepatitis c staging prediction using fine gaussian svm," Computers, Materials \& Continua, vol. 69, no.1, pp. 191-203, 2021.

[66] Ghazal, T. M., Kalra, D., \& Afifi, M. A. (2021). The Impact of Deploying the Internet of Things and How Will It Change Our Lives. Solid State Technology, 64(2).

[67] Taher M. Ghazal, Mohammed Kamrul Hasan, Rosilah Hasan, Shayla Islam, Siti Norul Huda Sheikh Abdullah, Mohammed A.M. Afifi, \& Deepak Karla. (2020). Security Vulnerabilities, Attachs, Threats and the Proposed Countermeasures for the Internet of 
Things Applications Solid State Technology, 63(1), 1566-1574. 